\title{
Testing the power properties of Fourier-Sollis Unit Root Test under symmetric and asymmetric reversions ${ }^{* 1}$
}

Atilla Hepkorucu ${ }^{2}$

Dr., Kastamonu Üniversitesi

ahepkorucu@gmail.com

(i) 0000-0001-6060-3135
Mehmet Çnar

Prof.Dr., Bursa Uludağ Üniversitesi mcinar@uludag.edu.tr

(D) $0000-0001-8441-243 \mathrm{X}$

\begin{abstract}
The unit root test proposed by Ranjbar et al. (2018) was examined for an alternative of stationary asymmetric exponential smooth transition autoregressive (AESTAR) under structural breaks. The situation that stands out as a deficiency in the mentioned study was that the model that does not includes the zero-mean structure not taken into account. On the contrary, the features of the zero-mean model should also had been explained. Because time-varying deterministic terms were removed from the time series for describing the structural breaks. The fact that no deterministic terms were formed due to the transformation during the redefinition of the difference equation indicates that the obtained structure should be evaluated in the model structure with zero-mean. This test methodology developed as an alternative is the interpretation of Sollis (2009) model under Fourier series that can be called FourierSollis test for zero-mean model condition. The critical values in terms of finite samples were calculated and the size and power properties were evaluated. The power properties of the Fourier-Sollis and Fourier-KSS tests were compared under the assumption of symmetric/asymmetric reversions. Under the asymmetric reversions, Fourier-Sollis test was found to be more successful. However, under the symmetric assumption, these tests can be used together.
\end{abstract}

Keywords: Unit Root AESTAR, Multi-

Structural Breaks.

JEL Codes: C1, C15

\section{Fourier-Sollis Birim Kök Testi'nin simetrik ve asimetrik yönelimleri için özelliklerinin belirlenmesi}

\section{ÖZ}

Ranjbar ve diğerleri (2018) tarafından önerilen birim kök testi, yapısal kırılmalar altında asimetrik yönelime izin veren üssel yumuşak geçişli otoregresif (AESTAR) model yapılarının durağanlıklarının incelenmesine izin vermektedir. Bu çalışmada eksiklik olarak göze çarpan deterministik terim yapısını içermeyen model yapısı dikkate alınmıştır. Çünkü zamana bağlı değişen deterministik terimler, yapısal kırılmayı tanımlamak adına zaman serisinden uzaklaştırılmaktadır. Fark denkleminin yeniden tanımlanması sırasında da dönüşümden dolayı herhangi bir deterministik terimin oluşmaması, elde edilen yapının sıfır ortalamaya sahip model yapısında değerlendirilmesi gerektiğine işaret etmektedir. $\mathrm{Bu}$ durum için, sonlu örneklem altında kritik değerler hesaplanmış ve boyut/güç özellikleri değerlendirilmiştir. Alternatif olarak geliştirilen bu test yöntemi Sollis (2009) modelinin Fourier serileri altında yorumlanması halindedir ve Fourier-Sollis olarak adlandırılmıștır. Fourier-Sollis ve Fourier-KSS testlerinin güç özellikleri simetrik/asimetrik yönelimleri altında karşllaştırılmıştır. Elde edilen sonuçlara göre, Fourier-Sollis testi asimetrik varsayım altında daha güçlü bulunmuştur. Ancak simetrik varsayım altında bu testler birlikte kullanılabilir.
Anahtar Kelimeler: Birim Kök Testleri, AESTAR, Çoklu Yapısal Kirılma.

JEL Kodları: C1, C15

*Atıf vermek için/To cite: "Hepkorucu, A., \& Çınar, M. (2021). Testing the power properties of Fourier-Sollis Unit Root Test under symmetric and asymmetric reversions. KOCATEPEIIBFD, 23(2), 171-181. https://doi.org/10.33707/akuiibfd.793591

Sorumlu Editör/Handling Editor: Prof.Dr. Jülide Yıldırım Öcal

1 The study was developed by compiling the data obtained from the doctoral thesis named "Doğrusal olmayan birim kök sınamalarının gelişimi ve bir test önerisi".

2 Sorumlu Yazar/Corresponded Author 


\section{Introduction}

The use of nonlinear model structures in the modeling of time series under the exponential smooth transition (ESTAR) model, the concept of global stationary has recently become popular. With this situation, it has become possible to determine the time series are stationary if the data generation process is nonlinear. The ESTAR model structure can be redefined by taking the first differences. It is an exponential function that gives non-linearity to the structure. The transition variable in nonlinear part is expressed as $y_{t-d}$. For the transition variable, it was assumed $\mathrm{d}=1$ to clarify empirical practices.

$y_{t}=\beta y_{t-1}+\gamma y_{t-1}\left(1-\exp \left(-\theta\left(y_{t-d}-c\right)^{2}\right)\right)+\varepsilon_{t}$

$\Delta y_{t}=\phi y_{t-1}+\gamma y_{t-1}\left(1-\exp \left(-\theta\left(y_{t-d}-c\right)^{2}\right)\right)+\varepsilon_{t}$

By taking first difference, the autoregressive term becomes as $\phi=\beta-1$. At the ESTAR structure $\theta$ term refers to reversion speed. Threshold parameter $(c)$ is an exhibition of time series behavior like a repressed or broken appearance when time-series approach it. Sarantis (1999) summarizes that ESTAR model, includes that regimes with similar dynamics, but the transition dynamics can be different. This can be explained as a change in regime when approaching the threshold. Also by moving away from the threshold term (c), causing the time series instability increases. So the stationary of the return series must be questioned under this assumption. As such, these parameters in the ESTAR model must be identified, thus stationary of time series can be accurately defined.

Kapetanios et al. (KSS) (2003) unit root test takes into account symmetrical ESTAR structure by assuming as threshold value is zero $c=0$. By differencing of applied first-order Taylor expansion of ESTAR model for the condition $\mathrm{y}=0$, auxiliary equation is obtained to suppress identification problem of nonlinear structure. The use of Taylor expansion especially ESTAR model structure in unit root tests is an application that eliminates the problem of the determination of coefficients of nonlinear structure. Method is based on redefining the difference equation with Taylor transformation.

$\Delta y_{t}=\delta y_{t-1}^{3}+u_{t}$

The unit root structure of time series is tested with $t$ statistic for the null hypothesis $\delta=0$ and its alternative $\delta<0$. The test statistic obtained as $t_{N L}=\hat{\delta} / s . e .(\hat{\delta})$ by auxiliary equation. The value $\hat{\delta}$ is estimated from the auxiliary regression with the least squares. There are two assumptions of the test which are being symmetric in mean reversion and being zero value of the threshold. This structure has been expanded by Sollis (2009) to consider the asymmetry and the threshold effect by Kruse (2011).

Sollis (2009) developed a unit root test for ESTAR models that considers symmetric or asymmetric reversions. It can be said to as a special case of KSS (2003) test. This model including the asymmetry as it is called AESTAR. In AESTAR, asymmetry is provided by using $\mathrm{S}_{t}\left(\theta_{2} ; y_{t-d}\right)$ logistic function and $\mathrm{G}_{t}\left(\theta_{1} ; y_{t-d}\right)$ exponential function as transition. The first order difference equation is shown below.

$$
\begin{aligned}
& \Delta y_{t}=\mathrm{G}_{t}\left(\theta_{1} ; y_{t-d}\right)\left\{\mathrm{S}_{t}\left(\theta_{2} ; y_{t-d}\right) \gamma_{1}+\left(1-\mathrm{S}_{t}\left(\theta_{2} ; y_{t-d}\right)\right) \gamma_{2}\right\} y_{t-1}+\varepsilon_{t}, \text { for } \varepsilon_{t} \sim \operatorname{iid}\left(0, \sigma^{2}\right) \\
& \mathrm{G}_{t}\left(\theta_{1} ; y_{t-d}\right)=1-\exp \left(-\theta_{1} y_{t-d}^{2}\right), \theta_{1} \geq 0 \\
& \mathrm{~S}_{t}\left(\theta_{2} ; y_{t-d}\right)=\left[1-\exp \left(-\theta_{2} y_{t-d}^{2}\right)\right]^{-1}, \theta_{2} \geq 0
\end{aligned}
$$

As in the KSS (2003) test, the use of auxiliary regression is performed under Taylor expansion. But if the same solution is used, $\theta_{2}, \gamma_{1}, \gamma_{2}$ these parameters will remain unknown. $\theta_{1}=0$ assumed for the first order Taylor expansion of the exponential transition function $\mathrm{G}_{t}\left(\theta_{1} ; y_{t-d}\right)$ becomes, 


$$
\Delta y_{t}=\gamma_{1} \theta_{1} y_{t-1}^{3} \mathrm{~S}_{t}\left(\theta_{2} ; y_{t-d}\right) \gamma_{1}+\gamma_{2} \theta_{1} y_{t-1}^{3}\left(1-\mathrm{S}_{t}\left(\theta_{2} ; y_{t-d}\right)\right)+\eta_{t}
$$

The error term $\eta_{t}$ contains both the error term $\varepsilon_{t}$ and residues $R_{t}$ from the Taylor transformation. Residues occur during Taylor expansion of the exponential function. This conversion is not sufficient because $\theta_{2}$ term is not defined. So, it is provided to change from $\mathrm{S}_{t}\left(\theta_{2} ; y_{t-d}\right)$ to $S_{t}^{*}\left(\theta_{2} ; y_{t-d}\right)$.

$$
\Delta y_{t}=\gamma_{1}^{*} \theta_{1} y_{t-1}^{3} S_{t}^{*}\left(\theta_{2} ; y_{t-d}\right) \gamma_{1}+\gamma_{2}^{*} \theta_{1} y_{t-1}^{3}\left(1-S_{t}^{*}\left(\theta_{2} ; y_{t-d}\right)\right)+\eta_{t}
$$

The transition becomes $S_{t}^{*}\left(\theta_{2} ; y_{t-d}\right)=\mathrm{S}_{t}\left(\theta_{2} ; y_{t-d}\right)-0.5$, which is explained for the limit value of the logistic function. The redefinition of the logistics function; $\gamma_{1}^{*}, \gamma_{2}^{*}$ will change to become a linear function of the terms $\gamma_{1}, \gamma_{2}$. When the Taylor transformation for $S_{t}^{*}\left(\theta_{2} ; y_{t-d}\right) \theta_{2}=0$ is applied to the redefined logistics function;

$\Delta y_{t}=a\left(\gamma_{2}^{*}-\gamma_{1}^{*}\right) \theta_{1} \theta_{2} y_{t-1}^{4}+\gamma_{2}^{*} \theta_{1} y_{t-1}^{3}+\eta_{t}$ is obtained. For $a=1 / 4$ the difference equation becomes;

$\Delta y_{t}=\phi_{1} y_{t-1}^{3}+\phi_{2} y_{t-1}^{4}+\eta_{t}$, the parameters of auxiliary regression $\phi_{1}=\gamma_{2}^{*} \theta_{1}$ and $\phi_{2}=a\left(\gamma_{2}^{*}-\gamma_{1}^{*}\right) \theta_{1} \theta_{2}$ contains. The corrected version of the difference equation is accepted as auxiliary regression.

$\Delta y_{t}=\phi_{1} y_{t-1}^{3}+\phi_{2} y_{t-1}^{4}+\sum_{j=1}^{\rho} \rho_{j} \Delta y_{t-j}+\eta_{t}$

It is mainly based on the unit root regime and the model structure that allows two symmetric and similar regiments. If time series approximate to the threshold parameter, it will behave like a series with a random walk. Sollis (2009) considers asymmetric reversion for ESTAR structure. However, it assumes that the threshold parameter is zero, such as KSS (2003).

In both tests, the assumption that the threshold value is zero was accepted. However, if statistically significant estimates of threshold value are encountered then this assumption is being loosened and will become a non-standard test procedure. For example, it can be assumed that real parity exchange rates behave asymmetrically despite the rise or fall of prices in the same proportion with the effect of domestic and foreign policy makers. It is observed that there is evidence that the real parities have an asymmetric structure against the US dollar (Sollis, 2002, p. 692). Later, Kruse (2011) test, which allows the threshold value of ESTAR structure to be evaluated as a non-zero value, is developed. Thus, the threshold value can take other than zero. However, the above tests consider nonlinearity but do not take into account structural breaks. Unit root tests under structural breaks have been used since Perron (1989). But identification of structural breaks on unit root tests by using Fourier transform methodology can be used as a new approach. Thus, varying regimes using Fourier series can be carried out to model, which are regardless of the type of breaks, number of breaks and where it occurs.

The explanation of structural breaks with Fourier series can be expressed by the time-based variation of the deterministic variables observed in the time series. Even if there is a structural break in terms of economic series, they will not be chaotic. This situation of the impact on economic data will not last forever from the moment it takes place. Market will get used to this new condition and the regime of the series will take on a finite structure again. No matter how many times there are breaks, an economic or financial data in terms of the market will maintain its finite structure. So, it seems quite logical to define all these deterministic variables and their changes by defining the time structure under the frequency structure. In this case, it becomes much more logical to question the stationarity of a series free from these effects. Because the problem is that unit root tests lose their power despite structural break. The purpose of all unit root tests that take into account the structural break developed since Perron (1989) is to eliminate this power loss. 
Becker et al. (2004), Enders and Lee (2004) and Becker et al. (2006) have used a special case of the Fourier expansion for the unknown number of refractions, for the deterministic component $\delta(t)$, which changes with time and is of unknown form. Let be a $\delta(t)$ deterministic component in the time series $y_{t}$.

$y_{t}=\delta(t)+v_{t}$ for $v_{t} \sim N\left(0, \sigma^{2}\right)$

$\delta(t)=\delta_{0}+\sum_{k=1}^{G} \delta_{1}^{k} \sin \left(\frac{2 \pi k t}{T}\right)+\sum_{k=1}^{G} \delta_{2}^{k} \cos \left(\frac{2 \pi k t}{T}\right)$

It is the number of frequencies $(k)$ in the Fourier function. $(t)$ is the trend term and $(T)$ is the sample size. The larger the number of frequency trials in the structure, the better approximation to the unknown form $\delta(t)$. As such, the null hypothesis of $\delta_{k} \neq 0$ must be rejected in order to find the optimal frequency number. The frequency number before the rejection can be preferred as the most suitable structure. The presence of a single statistically appropriate structure indicates that there is at least one structural change in the data generation mechanism. Model specification error may occur in the series defined by Fourier expansion. In order to solve the problem, the most suitable frequency should be selected (Ludlow \& Enders, 2000, p. 338-340). This method has an advantage over other tests that attempt endogenously for the form of structural break, since no a priori about its form is needed. This is the most practical part of its application. If the frequency value was known precisely, the presence of structural breaks in an unknown number and form could be tested. However, the $(k)$ frequency value is unknown. Finding the most appropriate frequency value $k$ that provides the most convergence by trying in order of $k=1,2, \ldots, 5$ and generally it can be seen that states $k=1$ or $k=2$ in applications (Becker et al., 2006, p. 390).

Another method is to choose the most appropriate frequency value that will minimize the sum of the squares of the error terms in the model. When the fractional values of another point $(k)$ are not used in the most appropriate frequency selection, the fact that the start and end values of the function are equal ensures that the breaks are temporary. The series $\left(y_{t}\right)$ should contain a break in the data generation mechanism, and the deterministic variable drawn from the structure should be determined by fourier modeling. The existence of the break can be questioned by testing the $H_{0}: \delta_{1}=\delta_{2}=0$ null hypothesis of the obtained deterministic variable, and the alternative hypothesis $H_{1}: \delta_{1} \neq \delta_{2} \neq 0$. The obtained $F$ statistic was named as $F_{\mu}(\tilde{k})$ and its distributions were determined by Monte-Carlo simulations and tabulated. Critical values of the test were established by Ludlow and Enders (2000). Becker et al. (2006) tabulated the test statistics for the asymptotic distribution of the $t$-statistics values according to the frequency values $(k)$ of the Fourier series.

The statistical significance of the obtained frequency structure indicates the presence of breaks. Christopoulos and León-Ledesma (2010) developed the new unit root tests explaining multiple structural breaks with Fourier series. Two of them are called Fourier-ADF and Fourier-KSS. Christopoulos and LeónLedesma (2010) tried to explain the Purchasing Power Parity (PPP) under breaks and nonlinear structure. In particular, price bubbles observed in exchange rates cause prices to deviate from the average and cause sudden breaks. This state caused by structural breaks do not prevent time series from reaching their longterm equilibrium. For this reason, the unit root tests used should allows breaks and also allow return to the mean. Similarly, in this study to development of Fourier-Sollis unit root test is combines the two previous test structures. This new test is formed by combining test mechanisms which takes asymmetric orientation into consideration Sollis (2009), and, which consider multiple structural breaks under the Fourier structure Christopoulos and León-Ledesma (2010). The main point for all models is that the unit root test is applied after the removing structural breaks that are accepted as a deterministic variable. By the obtained model errors, the unit root structure of the series can be examined. The return to mean can be considered non-linear or linear. The relevant models for all these cases are given below.

$\Delta v_{t}=p_{1} v_{t-1}\left(1-\exp \left(-\theta \Delta v_{t-i}^{2}\right)\right)+\sum_{j=1}^{p} \alpha_{j} \Delta v_{t-j}+u_{t}, \quad i=0,1, \ldots \ldots, L$.

$\Delta v_{t}=\lambda_{1} v_{t-1}^{3}+\sum_{j=1}^{p} \beta_{j} \Delta v_{t-j}+u_{t}$

In this study, it is aimed for model without any deterministic term to compare the power properties of Fourier-Sollis test with Fourier-KSS test under asymmetric and symmetric assumptions. The paper is organized as follows. Section I includes the ESTAR based unit root processes with Taylor expansion and 
definition structural breaks by Fourier transformation. Section II presents critical values, size and power properties of developed test. All these calculations are provided by using Eviews 10 program. Section III presents the conclusion under simulated results.

\section{Critical Values, Size and Power Properties of Fourier-Sollis Unit Root Test}

In the study, critical values of the Fourier-Sollis test were obtained and size and power properties for the finite samples were examined. Here, it is tried to determine that Fourier-Sollis test it can be used together or alternative of Fourier-KSS test. In their study, Ranjbar et al. (2018) developed an alternative test methodology for unit root determination in nonlinear time series, taking into account long-term equilibrium, structural breaks under asymmetric reversions. The selected nonlinear structure is the asymmetric exponential smooth threshold autoregressive AESTAR model. Model also includes symmetric ESTAR structure as a special case. Likewise, under structural breaks, it can be use the Fourier transformations. The model structure is discussed as follows.

$y_{t}=\delta(t)+v_{t}$ for $v_{t} \sim N\left(0, \sigma^{2}\right)$

$\delta(t)=\delta_{0}+\sum_{k=1}^{G} \delta_{1}^{k} \sin \left(\frac{2 \pi k t}{T}\right)+\sum_{k=1}^{G} \delta_{2}^{k} \cos \left(\frac{2 \pi k t}{T}\right)$

$\Delta v_{t}=\gamma_{1} \theta_{1} v_{t-1}^{3} \mathrm{~S}_{t}\left(\theta_{2} ; y_{t-d}\right) \gamma_{1}+\gamma_{2} \theta_{1} v_{t-1}^{3}\left(1-\mathrm{S}_{t}\left(\theta_{2} ; v_{t-d}\right)\right)+\eta_{t}$

$\Delta v_{t}=\phi_{1} v_{t-1}^{3}+\phi_{2} v_{t-1}^{4}+\sum_{j=1}^{\rho} \rho_{j} \Delta y_{t-j}+\eta_{t}$

When structural breaks are removed from the time series, deterministic terms are also swept away. This shortcoming is the removal of the time-varying deterministic terms on which the Fourier series are based when describing structural breaks from the model. It would be reasonable to examine such models under the mean zero model structure if using a method such as the Taylor transform under deterministic terms removal and the redefinition of the model does not produce a deterministic variable. This study is built on this assumption. This is the part where the paper differs from the original work and is seen as a deficiency to examine.

For the suggested Fourier-Sollis test, firstly critical values were tried to be determined. Under the $y_{t}=$ $y_{t-1}+\varepsilon_{t}$ structure where $\varepsilon_{\mathrm{t}} \sim\left(0, \sigma^{2}\right), 50000$ simulations are performed for $t=50,100,200,1000,10000$ finite sample values and critical values were obtained for $1 \%, 5 \%, 10 \%$ statistical significances. In addition, model degrees for Fourier transforms are determined for $k=1,2,3,4,5$.

The critical values are reported in Table 1 . When the results are evaluated, it is observed that the variation between the values decreases as the sample size approaches to 1000 . There is almost no difference between the critical values obtained for the sample sizes 1000 and 10000 .

Table 1: Critical Values for Fourier-Sollis Test

\begin{tabular}{ccccccc} 
Tample Size & & $\mathbf{k}=\mathbf{1}$ & $\mathbf{k}=\mathbf{2}$ & $\mathbf{k}=\mathbf{3}$ & $\mathbf{k}=\mathbf{4}$ & $\mathbf{k}=\mathbf{5}$ \\
\hline \multirow{2}{*}{$\mathbf{T}=\mathbf{5 0}$} & $1 \%$ & 10.436 & 8.587 & 8.011 & 7.698 & 7.433 \\
& $5 \%$ & 7.511 & 6.033 & 5.523 & 5.295 & 5.173 \\
& $10 \%$ & 6.272 & 4.948 & 4.518 & 4.327 & 4.225 \\
\hline \multirow{2}{*}{$\mathbf{T = 1 0 0}$} & $1 \%$ & 9.780 & 8.381 & 7.769 & 7.550 & 7.329 \\
& $5 \%$ & 7.353 & 6.104 & 5.592 & 5.374 & 5.271 \\
& $10 \%$ & 6.247 & 5.060 & 4.621 & 4.465 & 4.355 \\
\hline \multirow{2}{*}{$\mathbf{T}=\mathbf{2 0 0}$} & $1 \%$ & 9.847 & 8.387 & 7.792 & 7.604 & 7.456 \\
& $5 \%$ & 7.441 & 6.165 & 5.680 & 5.501 & 5.370 \\
& $10 \%$ & 6.325 & 5.160 & 4.731 & 4.560 & 4.452 \\
\hline \multirow{2}{*}{$\mathbf{T = 1 0 0 0}$} & $1 \%$ & 9.767 & 8.413 & 7.824 & 7.522 & 7.450 \\
& $5 \%$ & 7.472 & 6.215 & 5.738 & 5.481 & 5.425 \\
\hline
\end{tabular}

Hepkorucu \& Çınar, Testing the power properties of Fourier-Sollis Unit Root Test under symmetric and asymmetric reversions 
Table 1: Continue.

\begin{tabular}{lrllllll}
\hline & $10 \%$ & 6.391 & 5.201 & 4.781 & 4.606 & 4.507 \\
\hline \multirow{3}{*}{$\mathbf{T = 1 0 0 0 0}$} & $1 \%$ & 9.763 & 8.268 & 7.824 & 7.553 & 7.401 \\
& $5 \%$ & 7.540 & 6.191 & 5.745 & 5.525 & 5.382 \\
& $10 \%$ & 6.470 & 5.164 & 4.820 & 4.615 & 4.503 \\
\hline
\end{tabular}

Size properties of the developed unit root test under autocorrelated error terms were examined for finite sample and provided in Table 2. The data generation process was considered to be $y_{t}=y_{t-1}+\varepsilon_{t}$. Error terms are defined as $\varepsilon_{t}=\rho \varepsilon_{t-1}+u_{t}$ over the specified time interval. Here, the white noise term $u_{t} \sim i i d(0,1)$ is defined as the autocorrelation term $\rho=-0.5,0,0.5$ of the error terms. 20000 simulations were performed for $T=1000$.

Table 2. Size Properties for Fourier-Sollis Test

\begin{tabular}{ccccccc} 
& & $\mathbf{k}=\mathbf{1}$ & $\mathbf{k}=\mathbf{2}$ & $\mathbf{k}=\mathbf{3}$ & $\mathbf{k}=\mathbf{4}$ & $\mathbf{k}=\mathbf{5}$ \\
\hline $\boldsymbol{\rho}=-\mathbf{0 . 5}$ & $1 \%$ & 0.00995 & 0.00885 & 0.00975 & 0.00830 & 0.00815 \\
& $5 \%$ & 0.04725 & 0.04700 & 0.05100 & 0.04855 & 0.04565 \\
& $10 \%$ & 0.09585 & 0.09315 & 0.10155 & 0.09540 & 0.09345 \\
\hline & $1 \%$ & 0.00975 & 0.00935 & 0.01010 & 0.01030 & 0.01065 \\
\hline $\mathbf{\rho}=\mathbf{0}$ & $5 \%$ & 0.05315 & 0.04730 & 0.04900 & 0.04980 & 0.05165 \\
& $10 \%$ & 0.10635 & 0.09755 & 0.10075 & 0.09685 & 0.10320 \\
\hline & $1 \%$ & 0.01000 & 0.01000 & 0.00995 & 0.00945 & 0.00870 \\
& $5 \%$ & 0.05080 & 0.04775 & 0.04730 & 0.05155 & 0.04645 \\
\hline
\end{tabular}

When the size properties obtained for the different $k$ Taylor degrees were examined in Table 2 , it was found that the test did not have any size distortions. However, as the degree of model increases, there is little degradation in size.

The power characteristics of the developed Fourier - Sollis test were examined under the assumption of symmetric mean reversions as in FADF and Fourier-KSS tests. 10000 trials were tabulated for the Taylor model degrees with different coefficient values for $\mathrm{T}=\{100,250\}, \rho=\{-1.5,-1.0,-0.5,-0.1\}, \theta=$ $\{0.01,0.5,1.0\}, \delta_{0}=0, \delta_{1}=\delta_{2}=0.1$ and $\mathrm{k}=1,2,3$. The results are displayed in Table 3 . The critical values used for the power properties of the compared Fourier-KSS test, and the values obtained in the study of Christopoulos and León-Ledesma (2010) were used at Table 3. In determining the power characteristics, the degree of lag determined in terms of the most suitable model structure was selected depending on the value of the Akaike information criterion, with a maximum of $p=8$.

$y_{t}=\delta_{0}+\delta_{1} \sin \left(\frac{2 \pi k t}{T}\right)+\delta_{2} \cos \left(\frac{2 \pi k t}{T}\right)+v_{t}$

$v_{t}=p v_{t-1}\left(1-\exp \left(-\theta \Delta v_{t-1}^{2}\right)\right)+\sum_{j=1}^{\rho} \alpha_{j} \Delta v_{t-j}+u_{t}$

If the obtained results are summarized, Fourier-KSS test becomes stronger when $\rho$ values increase in negative direction. The fact that the value of $\rho$ moves away from zero causes the structure to converge to the unit root structure. As $\theta$ values increase positive direction, Fourier-Sollis test becomes stronger. The success of the tests increases as the transition rate $\theta$ increases between the regimes in the model structure. As a result, the power characteristics of the Fourier-Sollis test under symmetric assumption are similar to the Fourier-KSS test.

Power characteristics of the tests were examined under the assumption of symmetric mean reversion and the results obtained were compared for Fourier-KSS and Fourier-Sollis tests in Table 3. The power of the test decreases as the selected $\rho$ coefficient value approaches zero. This means that as parameter coefficient

Hepkorucu \& Çınar, Testing the power properties of Fourier-Sollis Unit Root Test under symmetric and asymmetric reversions 
$p$ moves away from zero, it approaches the unit root structure. When the parameter coefficient $\theta$ approaches unit value, similarly the power of the test increases. As the transition rate between regimes increases in the model structure, the success of the tests increases. Under the test results obtained, FourierSollis test is similar to Fourier-KSS test. These results show that the two tests can be used interchangeably for the assumption of symmetric mean reversions.

Table 3. Empirical Power Properties Under the Assumption of Symmetric Mean Reversion for FourierKSS and Fourier-Sollis Tests

\begin{tabular}{|c|c|c|c|c|c|c|c|}
\hline \multirow{2}{*}{\multicolumn{2}{|c|}{$\begin{array}{c}\delta_{1}=\delta_{2}=0.1 \\
t=100\end{array}$}} & \multicolumn{3}{|c|}{ Fourier-KSS } & \multicolumn{3}{|c|}{ Fourier-Sollis } \\
\hline & & \multirow{2}{*}{$\begin{array}{c}\mathbf{k}=\mathbf{1} \\
0.656\end{array}$} & \multirow{2}{*}{$\begin{array}{l}\mathbf{k}=\mathbf{2} \\
0.719\end{array}$} & \multirow{2}{*}{$\begin{array}{c}\mathbf{k}=3 \\
0.730\end{array}$} & \multirow{2}{*}{$\begin{array}{c}\mathbf{k}=\mathbf{1} \\
0.655\end{array}$} & \multirow{2}{*}{$\begin{array}{c}\mathbf{k}=\mathbf{2} \\
0.720\end{array}$} & \multirow{2}{*}{$\begin{array}{c}\mathbf{k}=\mathbf{3} \\
0.722\end{array}$} \\
\hline$p=-1.5$ & $\theta=0.1$ & & & & & & \\
\hline$p=-1.5$ & $\theta=0.5$ & 0.908 & 0.946 & 0.959 & 0.921 & 0.956 & 0.968 \\
\hline$p=-1.5$ & $\theta=1.0$ & 0.810 & 0.858 & 0.880 & 0.867 & 0.907 & 0.917 \\
\hline$p=-1.0$ & $\theta=0.1$ & 0.452 & 0.517 & 0.530 & 0.436 & 0.494 & 0.502 \\
\hline$p=-1.0$ & $\theta=0.5$ & 0.858 & 0.901 & 0.913 & 0.871 & 0.909 & 0.918 \\
\hline$p=-1.0$ & $\theta=1.0$ & 0.875 & 0.924 & 0.937 & 0.890 & 0.934 & 0.941 \\
\hline $\mathrm{p}=-0.5$ & $\theta=0.1$ & 0.242 & 0.235 & 0.234 & 0.233 & 0.210 & 0.209 \\
\hline$p=-0.5$ & $\theta=0.5$ & 0.605 & 0.692 & 0.728 & 0.594 & 0.689 & 0.711 \\
\hline $\mathrm{p}=-0.5$ & $\theta=1.0$ & 0.742 & 0.821 & 0.843 & 0.744 & 0.830 & 0.845 \\
\hline $\mathrm{p}=-0.1$ & $\theta=0.1$ & 0.243 & 0.192 & 0.183 & 0.261 & 0.207 & 0.200 \\
\hline$p=-0.1$ & $\theta=0.5$ & 0.192 & 0.165 & 0.160 & 0.190 & 0.156 & 0.148 \\
\hline $\mathrm{p}=-0.1$ & $\theta=1.0$ & 0.184 & 0.170 & 0.172 & 0.175 & 0.159 & 0.151 \\
\hline \multirow{2}{*}{\multicolumn{2}{|c|}{$\begin{array}{c}\delta_{1}=\delta_{2}=0.1 \\
t=250\end{array}$}} & \multicolumn{3}{|c|}{ Fourier-KSS } & \multicolumn{3}{|c|}{ Fourier-Sollis } \\
\hline & & $k=1$ & $k=2$ & $k=3$ & $k=1$ & $k=2$ & $k=3$ \\
\hline$p=-1.5$ & $\theta=0.1$ & 0.894 & 0.932 & 0.949 & 0.916 & 0.952 & 0.964 \\
\hline$p=-1.5$ & $\theta=0.5$ & 0.998 & 0.999 & 0.999 & 0.999 & 1.000 & 1.000 \\
\hline$p=-1.5$ & $\theta=1.0$ & 0.981 & 0.987 & 0.991 & 0.988 & 0.994 & 0.995 \\
\hline $\mathrm{p}=-1.0$ & $\theta=0.1$ & 0.761 & 0.839 & 0.861 & 0.786 & 0.866 & 0.889 \\
\hline $\mathrm{p}=-1.0$ & $\theta=0.5$ & 0.990 & 0.995 & 0.995 & 0.995 & 0.998 & 0.998 \\
\hline $\mathrm{p}=-1.0$ & $\theta=1.0$ & 0.993 & 0.997 & 0.998 & 0.996 & 0.998 & 0.999 \\
\hline $\mathrm{p}=-0.5$ & $\theta=0.1$ & 0.378 & 0.470 & 0.483 & 0.379 & 0.466 & 0.479 \\
\hline $\mathrm{p}=-0.5$ & $\theta=0.5$ & 0.909 & 0.949 & 0.958 & 0.935 & 0.966 & 0.974 \\
\hline $\mathrm{p}=-0.5$ & $\theta=1.0$ & 0.954 & 0.981 & 0.985 & 0.969 & 0.988 & 0.991 \\
\hline $\mathrm{p}=-0.1$ & $\theta=0.1$ & 0.188 & 0.150 & 0.134 & 0.204 & 0.161 & 0.151 \\
\hline $\mathrm{p}=-0.1$ & $\theta=0.5$ & 0.199 & 0.252 & 0.241 & 0.197 & 0.235 & 0.231 \\
\hline$p=-0.1$ & $\theta=1.0$ & 0.250 & 0.351 & 0.349 & 0.242 & 0.340 & 0.335 \\
\hline
\end{tabular}

In Table 4, the power characteristics of the tests under asymmetric assumption were examined as in Sollis (2009). Asymmetry strengthens as the $\gamma_{1}$ and $\gamma_{2}$ values determined as the transition function coefficients move away from each other. If asymmetry increases, Fourier-Sollis test is more powerful than Fourier-KSS test. Inversely, if the $\gamma_{1}$ and $\gamma_{2}$ values approach each other, asymmetry decreases and Fourier-KSS test becomes more powerful. This situation is more clearly observed when the Fourier frequency degree, the number of samples and the $\theta_{1}$ parameter values are increase. 
Table 4. Empirical Power Properties Under the Assumption of Asymmetric Mean Reversion for FourierKSS and Fourier-Sollis Tests

\begin{tabular}{|c|c|c|c|c|c|}
\hline \multicolumn{2}{|c|}{$\mathrm{T}=100, \delta_{i}=0.1, k=1$} & \multicolumn{2}{|c|}{$\theta_{1}=0.1$} & \multicolumn{2}{|c|}{$\theta_{1}=1$} \\
\hline$\gamma_{1}$ & $\gamma_{2}$ & Fourier-KSS & Fourier-Sollis & Fourier-KSS & Fourier-Sollis \\
\hline-0.05 & -1.00 & 0.347 & 0.383 & 0.593 & 0.687 \\
\hline-0.05 & -0.90 & 0.340 & 0.357 & 0.551 & 0.635 \\
\hline-0.05 & -0.70 & 0.279 & 0.283 & 0.458 & 0.504 \\
\hline-0.05 & -0.30 & 0.175 & 0.157 & 0.235 & 0.223 \\
\hline-0.05 & -0.10 & 0.113 & 0.100 & 0.129 & 0.114 \\
\hline-0.05 & -0.05 & 0.096 & 0.085 & 0.109 & 0.093 \\
\hline-0.10 & -1.00 & 0.466 & 0.490 & 0.719 & 0.831 \\
\hline-0.10 & -0.90 & 0.437 & 0.451 & 0.684 & 0.793 \\
\hline-0.10 & -0.70 & 0.369 & 0.373 & 0.590 & 0.655 \\
\hline-0.10 & -0.30 & 0.225 & 0.212 & 0.336 & 0.320 \\
\hline-0.10 & -0.10 & 0.140 & 0.123 & 0.169 & 0.150 \\
\hline-0.10 & -0.05 & 0.112 & 0.100 & 0.130 & 0.118 \\
\hline-0.30 & -1.00 & 0.745 & 0.755 & 0.915 & 0.963 \\
\hline-0.30 & -0.90 & 0.715 & 0.717 & 0.910 & 0.955 \\
\hline-0.30 & -0.70 & 0.640 & 0.635 & 0.887 & 0.919 \\
\hline-0.30 & -0.30 & 0.392 & 0.362 & 0.648 & 0.633 \\
\hline-0.30 & -0.10 & 0.222 & 0.202 & 0.326 & 0.307 \\
\hline-0.30 & -0.05 & 0.170 & 0.144 & 0.228 & 0.220 \\
\hline \multicolumn{2}{|c|}{$\mathrm{T}=250, \delta_{i}=0.1, k=1$} & \multicolumn{2}{|c|}{$\theta_{1}=0.1$} & \multicolumn{2}{|c|}{$\theta_{1}=1$} \\
\hline$\gamma_{1}$ & $\gamma_{2}$ & Fourier-KSS & Fourier-Sollis & Fourier-KSS & Fourier-Sollis \\
\hline-0.05 & -1.00 & 0.678 & 0.841 & 0.698 & 0.997 \\
\hline-0.05 & -0.90 & 0.666 & 0.818 & 0.692 & 0.959 \\
\hline-0.05 & -0.70 & 0.623 & 0.750 & 0.674 & 0.923 \\
\hline-0.05 & -0.30 & 0.456 & 0.496 & 0.557 & 0.673 \\
\hline-0.05 & -0.10 & 0.251 & 0.238 & 0.310 & 0.310 \\
\hline-0.05 & -0.05 & 0.171 & 0.158 & 0.207 & 0.200 \\
\hline-0.10 & -1.00 & 0.882 & 0.970 & 0.851 & 0.996 \\
\hline-0.10 & -0.90 & 0.882 & 0.966 & 0.847 & 0.995 \\
\hline-0.10 & -0.70 & 0.847 & 0.933 & 0.858 & 0.993 \\
\hline-0.10 & -0.30 & 0.713 & 0.743 & 0.787 & 0.887 \\
\hline-0.10 & -0.10 & 0.402 & 0.385 & 0.493 & 0.493 \\
\hline-0.10 & -0.05 & 0.262 & 0.247 & 0.309 & 0.304 \\
\hline-0.30 & -1.00 & 0.996 & 0.999 & 0.975 & 0.998 \\
\hline-0.30 & -0.90 & 0.995 & 0.999 & 0.980 & 0.998 \\
\hline-0.30 & -0.70 & 0.994 & 0.998 & 0.982 & 0.997 \\
\hline-0.30 & -0.30 & 0.965 & 0.977 & 0.983 & 0.990 \\
\hline-0.30 & -0.10 & 0.702 & 0.737 & 0.798 & 0.885 \\
\hline-0.30 & -0.05 & 0.468 & 0.505 & 0.566 & 0.681 \\
\hline \multicolumn{2}{|c|}{$\mathrm{T}=100, \delta_{i}=0.1, k=2$} & \multicolumn{2}{|c|}{$\theta_{1}=0.1$} & \multicolumn{2}{|c|}{$\theta_{1}=1$} \\
\hline$\gamma_{1}$ & $\gamma_{2}$ & Fourier-KSS & Fourier-Sollis & Fourier-KSS & Fourier-Sollis \\
\hline-0.05 & -1.00 & 0.450 & 0.473 & 0.647 & 0.744 \\
\hline-0.05 & -0.90 & 0.424 & 0.441 & 0.625 & 0.712 \\
\hline-0.05 & -0.70 & 0.367 & 0.374 & 0.543 & 0.599 \\
\hline-0.05 & -0.30 & 0.224 & 0.200 & 0.318 & 0.305 \\
\hline-0.05 & -0.10 & 0.130 & 0.109 & 0.167 & 0.143 \\
\hline-0.05 & -0.05 & 0.095 & 0.081 & 0.115 & 0.097 \\
\hline-0.10 & -1.00 & 0.587 & 0.609 & 0.783 & 0.883 \\
\hline-0.10 & -0.90 & 0.562 & 0.578 & 0.763 & 0.858 \\
\hline-0.10 & -0.70 & 0.502 & 0.490 & 0.704 & 0.767 \\
\hline-0.10 & -0.30 & 0.315 & 0.284 & 0.463 & 0.455 \\
\hline-0.10 & -0.10 & 0.172 & 0.144 & 0.230 & 0.202 \\
\hline-0.10 & -0.05 & 0.127 & 0.105 & 0.159 & 0.139 \\
\hline-0.30 & -1.00 & 0.856 & 0.866 & 0.943 & 0.974 \\
\hline-0.30 & -0.90 & 0.836 & 0.843 & 0.940 & 0.974 \\
\hline-0.30 & -0.70 & 0.776 & 0.773 & 0.926 & 0.956 \\
\hline
\end{tabular}


Table 4. Continue.

\begin{tabular}{|c|c|c|c|c|c|}
\hline-0.30 & -0.30 & 0.550 & 0.518 & 0.791 & 0.785 \\
\hline-0.30 & -0.10 & 0.304 & 0.274 & 0.462 & 0.449 \\
\hline-0.30 & -0.05 & 0.225 & 0.200 & 0.316 & 0.301 \\
\hline \multicolumn{2}{|c|}{$\mathrm{T}=250, \delta_{i}=0.1, k=2$} & \multicolumn{2}{|c|}{$\theta_{1}=0.1$} & \multicolumn{2}{|c|}{$\theta_{1}=1$} \\
\hline$\gamma_{1}$ & $\gamma_{2}$ & Fourier-KSS & Fourier-Sollis & Fourier-KSS & Fourier-Sollis \\
\hline-0.05 & -1.00 & 0.780 & 0.909 & 0.763 & 0.981 \\
\hline-0.05 & -0.90 & 0.771 & 0.900 & 0.764 & 0.973 \\
\hline-0.05 & -0.70 & 0.743 & 0.861 & 0.762 & 0.959 \\
\hline-0.05 & -0.30 & 0.615 & 0.673 & 0.685 & 0.800 \\
\hline-0.05 & -0.10 & 0.388 & 0.375 & 0.459 & 0.460 \\
\hline-0.05 & -0.05 & 0.260 & 0.234 & 0.310 & 0.294 \\
\hline-0.10 & -1.00 & 0.933 & 0.990 & 0.893 & 0.998 \\
\hline-0.10 & -0.90 & 0.930 & 0.986 & 0.937 & 0.998 \\
\hline-0.10 & -0.70 & 0.917 & 0.978 & 0.897 & 0.996 \\
\hline-0.10 & -0.30 & 0.843 & 0.881 & 0.879 & 0.951 \\
\hline-0.10 & -0.10 & 0.585 & 0.576 & 0.668 & 0.668 \\
\hline-0.10 & -0.05 & 0.388 & 0.375 & 0.453 & 0.456 \\
\hline-0.30 & -1.00 & 0.998 & 1.000 & 0.983 & 0.999 \\
\hline-0.30 & -0.90 & 0.999 & 1.000 & 0.985 & 0.998 \\
\hline-0.30 & -0.70 & 0.998 & 0.999 & 0.989 & 0.998 \\
\hline-0.30 & -0.30 & 0.989 & 0.994 & 0.993 & 0.997 \\
\hline-0.30 & -0.10 & 0.837 & 0.880 & 0.875 & 0.952 \\
\hline-0.30 & -0.05 & 0.616 & 0.670 & 0.686 & 0.805 \\
\hline \multicolumn{2}{|c|}{$\mathrm{T}=100, \delta_{i}=0.1, k=3$} & \multicolumn{2}{|c|}{$\theta_{1}=0.1$} & \multicolumn{2}{|c|}{$\theta_{1}=1$} \\
\hline$\gamma_{1}$ & $\gamma_{2}$ & Fourier-KSS & Fourier-Sollis & Fourier-KSS & Fourier-Sollis \\
\hline-0.05 & -1.00 & 0.483 & 0.523 & 0.677 & 0.812 \\
\hline-0.05 & -0.90 & 0.450 & 0.477 & 0.652 & 0.770 \\
\hline-0.05 & -0.70 & 0.389 & 0.399 & 0.587 & 0.670 \\
\hline-0.05 & -0.30 & 0.244 & 0.217 & 0.365 & 0.345 \\
\hline-0.05 & -0.10 & 0.140 & 0.111 & 0.177 & 0.145 \\
\hline-0.05 & -0.05 & 0.106 & 0.076 & 0.120 & 0.096 \\
\hline-0.10 & -1.00 & 0.639 & 0.655 & 0.815 & 0.914 \\
\hline-0.10 & -0.90 & 0.620 & 0.630 & 0.798 & 0.896 \\
\hline-0.10 & -0.70 & 0.548 & 0.541 & 0.742 & 0.821 \\
\hline-0.10 & -0.30 & 0.347 & 0.304 & 0.516 & 0.485 \\
\hline-0.10 & -0.10 & 0.187 & 0.149 & 0.273 & 0.225 \\
\hline-0.10 & -0.05 & 0.131 & 0.103 & 0.177 & 0.146 \\
\hline-0.30 & -1.00 & 0.899 & 0.902 & 0.951 & 0.979 \\
\hline-0.30 & -0.90 & 0.883 & 0.881 & 0.951 & 0.978 \\
\hline-0.30 & -0.70 & 0.840 & 0.831 & 0.943 & 0.965 \\
\hline-0.30 & -0.30 & 0.643 & 0.419 & 0.845 & 0.835 \\
\hline-0.30 & -0.10 & 0.344 & 0.304 & 0.522 & 0.493 \\
\hline-0.30 & -0.05 & 0.243 & 0.221 & 0.359 & 0.337 \\
\hline \multicolumn{2}{|c|}{$\mathrm{T}=250, \delta_{i}=0.1, k=3$} & \multicolumn{2}{|c|}{$\theta_{1}=0.1$} & \multicolumn{2}{|c|}{$\theta_{1}=1$} \\
\hline$\gamma_{1}$ & $\gamma_{2}$ & Fourier-KSS & Fourier-Sollis & Fourier-KSS & Fourier-Sollis \\
\hline-0.05 & -1.00 & 0.810 & 0.940 & 0.777 & 0.989 \\
\hline-0.05 & -0.90 & 0.803 & 0.934 & 0.775 & 0.983 \\
\hline-0.05 & -0.70 & 0.767 & 0.897 & 0.775 & 0.972 \\
\hline-0.05 & -0.30 & 0.665 & 0.730 & 0.724 & 0.849 \\
\hline-0.05 & -0.10 & 0.438 & 0.424 & 0.506 & 0.517 \\
\hline-0.05 & -0.05 & 0.283 & 0.267 & 0.334 & 0.313 \\
\hline-0.10 & -1.00 & 0.944 & 0.993 & 0.907 & 0.999 \\
\hline-0.10 & -0.90 & 0.944 & 0.993 & 0.899 & 0.998 \\
\hline-0.10 & -0.70 & 0.932 & 0.984 & 0.913 & 0.996 \\
\hline-0.10 & -0.30 & 0.884 & 0.921 & 0.906 & 0.968 \\
\hline-0.10 & -0.10 & 0.636 & 0.628 & 0.719 & 0.721 \\
\hline-0.10 & -0.05 & 0.435 & 0.421 & 0.506 & 0.509 \\
\hline-0.30 & -1.00 & 0.999 & 1.000 & 0.987 & 0.999 \\
\hline-0.30 & -0.90 & 0.998 & 1.000 & 0.988 & 0.999 \\
\hline
\end{tabular}

Hepkorucu \& Çınar, Testing the power properties of Fourier-Sollis Unit Root Test under symmetric and asymmetric reversions 
Table 4. Continue.

\begin{tabular}{llllll}
\hline-0.30 & -0.70 & 0.998 & 1.000 & 0.991 & 0.999 \\
-0.30 & -0.30 & 0.994 & 0.997 & 0.993 & 0.998 \\
-0.30 & -0.10 & 0.879 & 0.922 & 0.909 & 0.969 \\
-0.30 & -0.05 & 0.663 & 0.733 & 0.723 & 0.856 \\
\hline
\end{tabular}

If Table 4. generally reviewed, the power of the Fourier-Sollis test increases with the number of samples and gives better results than the Fourier-KSS test in terms of power characteristics under the assumption of asymmetric mean reversions. It is observed that the power of Fourier-Sollis test becomes more significant as the difference between asymmetry and transition rates increases. In case of symmetrical reversions, that is $\gamma_{1}=\gamma_{2}$, the Fourier-KSS test was found to be more powerful than the Fourier-Sollis test. Because of first order Taylor transformation with the variable in $y_{t-1}^{4}$, the auxiliary regression of the AESTAR model became more convergent than the auxiliary regression of the ESTAR model. In the light of these results, Fourier-Sollis test is indisputably more powerful under the assumption of asymmetric mean reversion.

\section{Conclusions}

In this study, the powers of Fourier-Sollis and Fourier-KSS tests under symmetric and asymmetric reversions were compared. Under the symmetrical assumption, it was observed that the Fourier-Sollis test was close to the Fourier-KSS test in terms of power. Under the asymmetric assumption, the Fourier-Sollis test was found to be stronger than the Fourier-KSS test. In this case, it is observed that Fourier-Sollis test can be used as a alternative of Fourier-KSS test under structural break of asymmetric or symmetric reversions. If it is accepted that the wave structure can be deviated for the series that is applied Fourier transform, as an example the symmetric mean reversion in the data generation mechanism can convert to asymmetric. In this case, the use of Fourier-Sollis test, which takes into account the asymmetric mean reversion, will ensure the unit root structure of time series is determined much more accurately.

The developed test structure has been found to be useful for unit root detection for asymmetric ESTAR structures under structural break. Especially in the model structure, unlike the original study, deterministic terms were not included. Because it makes no sense to allow deterministic terms in the difference term under these conditions. So, if there is an expression for any deterministic term in the redefined difference equation, it is a property left over from the remnants of the Taylor transformation. The solution to this problem arising from residuals is to increase the lag degree of the model.

Statement of Contribution of Researchers: The authors declared that their contribution to the study is equal.

Statement of Support and Acknowledgment: The authors declared that the study is not received support from any person or institution.

Conflict Statement: The authors declare that there is no conflict of interest for himself and third parties.

Statement of Ethics Committee Report Requirement: The authors state that there is no need for an ethics committee report in the article.

Hepkorucu \& Çınar, Testing the power properties of Fourier-Sollis Unit Root Test under symmetric and asymmetric reversions 


\section{References}

Becker R., Walter E. \& Junsoo L. (2006). A stationarity test in the presence of an unknown number of smooth breaks, Journal of Time Series Analysis, 27(3). p. 381-409. https://doi:10.1111/j.14679892.2006.00478.x

Becker R., Walter E. \& Stan H. (2004). A general test for time dependence in parameters, Journal of Applied Econometrics, 19(7). p. 899-906.

Christopoulos, D. K., \& León-Ledesma, M. A. (2010). Smooth breaks and non-linear mean reversion: PostBretton Woods real exchange rates. Journal of International Money and Finance, 29(6), p. 1076-1093. https://doi:10.1016/j.jimonfin.2010.02.003

Enders W., \& Junsoo L. (2004). Testing for a unit root with a nonlinear Fourier function, Econometric Society, 2004 Far Eastern Meetings, Vol:457, p. 1-47.

Escribano, A., \& Jordá, O. (2001). Testing nonlinearity: Decision rules for selecting between logistic and exponential STAR models. Spanish Economic Review, 3(3), p. 193-209.

Granger, C. W., \& Lee, T. H. (1989). Investigation of production, sales and inventory relationships using multicointegration and non-symmetric error correction models. Journal of Applied Econometrics, 4(1), p. 145-159.

Kapetanios, G., Shin, Y., \& Snell, A. (2003). Testing for a unit root in the nonlinear STAR framework. Journal of econometrics, 112(2), p. 359-379. https://doi.org/10.1016/S0304-4076(02)00202-6

Kruse, R. (2011). A new unit root test against ESTAR based on a class of modified statistics. Statistical Papers, 52(1), p. 71-85. https://doi.org/10.1007/s00362-009-0204-1

Ludlow, J., \& Enders, W. (2000). Estimating non-linear ARMA models using Fourier coefficients. International Journal of Forecasting, 16(3), p. 333-347.

Neftci, S. N. (1984). Are economic time series asymmetric over the business cycle?. Journal of Political Economy, 92(2), p. 307-328.

Perron, P. (1989). The great crash, the oil price shock, and the unit root hypothesis. Econometrica: Journal of the Econometric Society, p.1361-1401.

Ranjbar, O., Chang, T., Elmi, Z. M., \& Lee, C. C. (2018). A new unit root test against asymmetric ESTAR nonlinearity with Smooth Breaks. Iranian Economic Review,22(1), p. 51-62. https://doi.org/10.22059/IER.2018.65349

Sarantis, N. (1999). Modeling non-linearities in real effective exchange rates. Journal of International Money and Finance, $18(1)$, p. 27-45.

Sollis, R. (2009). A simple unit root test against asymmetric STAR nonlinearity with an application to real exchange rates in Nordic countries. Economic Modelling, 26(1), p. 118-125. https://doi.org/10.1016/j.econmod.2008.06.002

Sollis, R., Leybourne, S., \& Newbold, P. (2002). Tests for symmetric and asymmetric nonlinear mean reversion in real exchange rates. Journal of Money, Credit and Banking, p. 686-700.

Terasvirta, T., \& Anderson, H. M. (1992). Characterizing nonlinearities in business cycles using smooth transition autoregressive models. Journal of Applied Econometrics, 7(1), p. 119-136. 